\title{
Modeling and Simulation Competency Center for Mature Enterprises
}

\author{
Jorge Cordeiro Duarte and Mamede Lima-Marques \\ Centre for Research on Architecture of Information \\ University of Brasilia - UnB \\ \{jorgecduarte,mamede\}@unb.br \\ http://www.cpai.unb.br
}

\begin{abstract}
Modeling and simulation (M\&S) play a significant role in management and decision making in modern enterprises. New methods, techniques and tools have been arising to help organizations to succeed in $M \& S$. We can find many cases of successfully application of M\&S in organizations, but normally departmental efforts. Mature enterprises must have M\&S managed and optimized efforts in all their departments. Enterprise wide $M \& S$ efforts are challenging and few enterprises succeed on it. This challenge is little explored in literature. Enterprise wide $M \& S$ is a complex and multidisciplinary effort and need an integrated view. This paper explores M\&S enterprise wide efforts. It offers an integrated approach that links technical and behavioral aspects. It also recommends an enterprise competence center in order to organize and drive the modeling and simulation efforts.
\end{abstract}

Keywords. Modeling and simulation, BPM, EA, Ontologies, Competency Center

\section{Introduction}

Modeling has always been at the core of both organizational design and information systems development [24]. Enterprise Modeling (EM) has attracted attention of researchers from a variety of fields [52] and this interest results in a great number of modeling approaches, methods, techniques and tools [24].

Enterprises are complex environments. Models help to filter out irrelevant complexities, so that efforts can be directed toward the most important parts of the system under study [52]. Models also permit simulation approaches to give an understanding of possible scenarios for improvement [29].

Modeling and Simulation (M\&S) strategies have evolved from departmental efforts to enterprise wide approaches with the Business Process Management (BPM) concepts [20]. BPM begins with process modeling but permits simulation, automation and control of organizational processes. 
An M\&S initiative needs several types of models in different levels of detail. Process models need to be integrated with data and system models. Thus, another necessity has appeared: to integrate models and give different visions of the same model. Market and researchers call these efforts as Enterprise Architecture (EA) initiatives [34].

With the ever crescent enterprise complexity we can find other kinds of models in organization: Knowledge models. These kinds of models, named ontologies, show relations between elements of organization and help the documentation and interchange of knowledge, reducing complexity [33].

Mature enterprises are recognized by their capacity of coordinating continuously improving results [10]. Maturity is provided by repeatable, well-defined and managed programs. So, mature enterprises must have well-defined, repeatable and managed M\&S, BPM, EA and ontologies programs.

M\&S, BPM, EA and ontologies are extensively discussed in literature, but they are little practiced in organizations. The factors that influence an integrated and more intensive use of these technologies are an open question in research. This study addresses this question contributing with a multidisciplinary and integrated enterprise wide approach. It discusses $\mathrm{M} \& \mathrm{~S}$ and related modeling approaches, analyses its integration and discuss organizational issues leading to successful accomplishment.

This paper is organized as follows: Section 2 presents the evolution of enterprise modeling and simulation. Section 3 explores the concepts and benefits of BPM and EA. Section 4 analyses the relation of M\&S and knowledge modeling. Section 5 discusses M\&S and enterprise maturity. Section 6 summarizes the technology and organization sides of modeling and proposes an integrated approach for modeling and simulation. Section 7 summarizes and proposes future works.

\section{The Evolution of Enterprise Modeling and Simulation}

Smith and Fingar describe three waves of BPM [53]. The first wave is related with Taylor's scientific management from the 1920's. Organization modeling at that time has internal focus, normally at departmental level, with collaborative approaches like Total Quality Management (TQM) ([6], [12], [16]). The main techniques for modeling were flowcharts and tools had few resources. Modeling was not yet considered. Models for specific proposes like UML, for development of information systems [3] and MER, for design of data bases [8], came to scene.

The second wave has come with the radical reengineering attempts in the 1990's such as Business Process Reengineering (BPR) [26] and ERP [37]. The focus was to look inside the organization to reduce cost with automation and optimization. It proposes to change radically processes in a centralized top down approach [35]. New modeling techniques and tools appeared, like IDEF0 [28] and Visio. Simulation begins to have attention of researchers [24].

The third wave began almost at the same time as an alternative to the second wave. It is still present and is characterized by the advent of BPM concepts [20]. The Focus has shifted to outside the company boundaries because of the competition and technology changes [60]. Enterprise modeling became sophisticated, using complex techniques with repository of objects in databases [20]. 
Many modeling languages have appeared to supply business demand, like EPC [50], RAD [44], DEMO [17], Petri-nets [57], YAWL [58], Y*[32] and BPMN [54]. Each technique has different resources and focus, so we can find many studies evaluating ([1], [36]) and classifying the alternatives ([20], [24], [39], [59]). Some techniques are more popular than others [59]. Each language has its purpose and an organization needs many kinds of models, each one with a specific language [1].

Many frameworks and methodologies were proposed to organize the efforts of modeling. They connect different models in a logical way, like Zachman framework [61], FEA framework [23] and TOGAF methodology [56].

Increased globalization, intense competition, and technological change have forced organization to invest in better and integrated processes [38] so the concept of Business Process Management (BPM) was largely adopted [53]. BPM considers not only modeling but also analysis, simulation and control of processes [40]. Many BPM tools were launched to the market, adopting and integrating some of the above cited languages [41].

Simulation continues to attract researchers' attention ([2], [4], [29], [45]). Simulation has many quantitative metrics that can be addressed including costs, cycle time, serviceability and resource utilization [4]. Nowadays, many BPM tools incorporate support for simulation [41].

Research is evolving to enterprise wide approaches following the business requirements. So, we reach Enterprise Architecture (EA) and Knowledge Modeling (KM) approaches which are discussed in the following sections.

\section{M\&S Strategies and Their Relation with BPM and EA}

As shown in the previous section, M\&S is related with BPM approach. Business processes have been at the heart of business and technology improvement under the guise of many terms and methodologies. BPM is related with Business Process Engineering, Business Process Management, Business Process Execution, Total Quality Management, Process Improvement, Business Process Modeling and Workflow [42].

BPM can be seen as a continuum between languages, tools and frameworks [41] as we can see in figure 1. BPM tools can provide the following resources: process modeling, executable design, human task design, integration, simulation, business rules, content, team collaboration, performance management [52]. BPM tools are not equal. The resources depend on the focus of the product. This focus can be human centric, production workflow centric and case management centric [52].

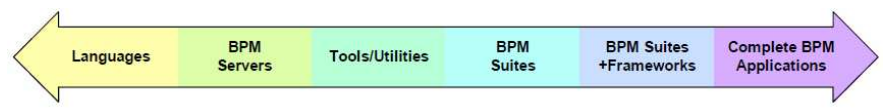

Figure 1 - The BPM Product Continuum (Miers, ,2006)

$\mathrm{M} \& \mathrm{~S}$ is also related with enterprise wide modeling approaches like EA. EA is a coherent whole of principles, methods, and models. EA is used in the design and realization of an enterprise's organizational structure, business processes, information 
systems, and infrastructure [34]. EA identifies the main components of an organization and how this components system function together to achieve defined business objectives [60]. EA includes high-level business aspects like business goals, processes and practices as figure 2 shows [38].

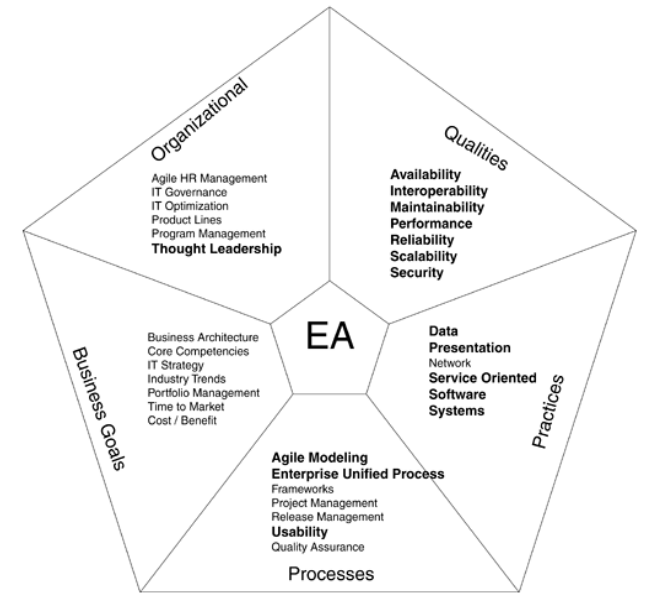

Figure 2 - Pentagon for architecture agility (McGovern/Stevens, 2003)

EA can use a variety of languages, including flowcharts, UML, MER, Eventdriven Process Chains, Yet another Workflow Language, and the Business Process Modeling Notation. EA can have also a specific language like Archimate (Figure 3) [34].

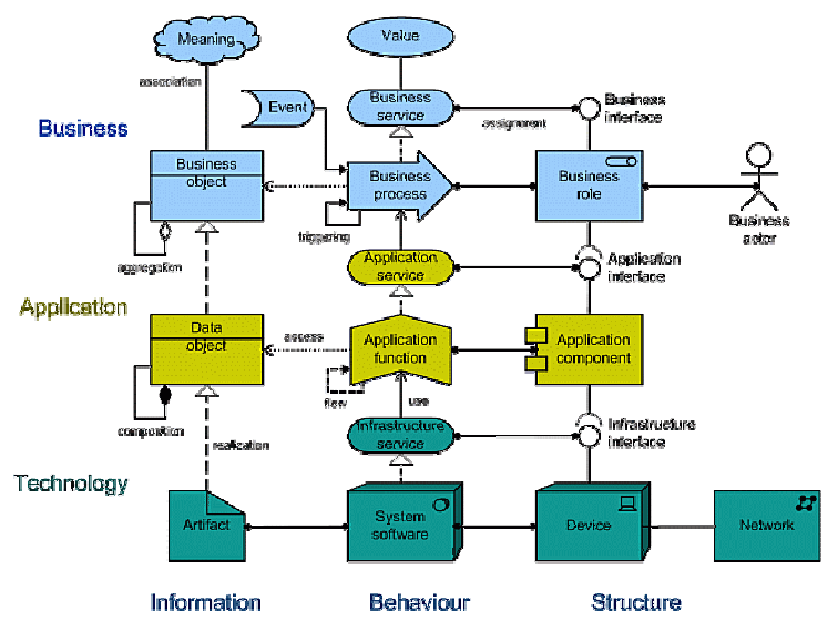

Figure 3 - Archimate language (Lankhorst et al., 2005)

\section{M\&S and Knowledge Modeling}


With the advent of enterprise wide modeling approaches, information and knowledge modeling is gaining attention of researchers ([15], [19]). Until recently information management was a subject related with data modeling and restricted to the information system area.

In fact, data modeling is one of the most mature methodologies in information systems (IS). It has well established standards and tools [8]. It is well accepted by the community. The Data Administrator is a well recognized position.

Despite many research made by well known authors, like Davenport [14], Choo[9] and Everdeen ([21], [22]), information modeling in business side has not been understood yet and has little practice in organizations.

Information Science (IS) is a well established discipline but gives little attention to information in organizations. This side of information has always been interpreted by IS researchers as something related with databases [48].

Recently we can find works in organizational information modeling related with semantics and ontologies ([5], [33], [46]). Ontology is defined as a specification of a conceptualization [25]. Ontologies provide a number of useful features for knowledge representation [6].

Ontologies can vary in expressivity and formalisation. Figure 4 shows this evolution. Ontologies have specific languages of modeling like OWL and specific tools like Protege [18].

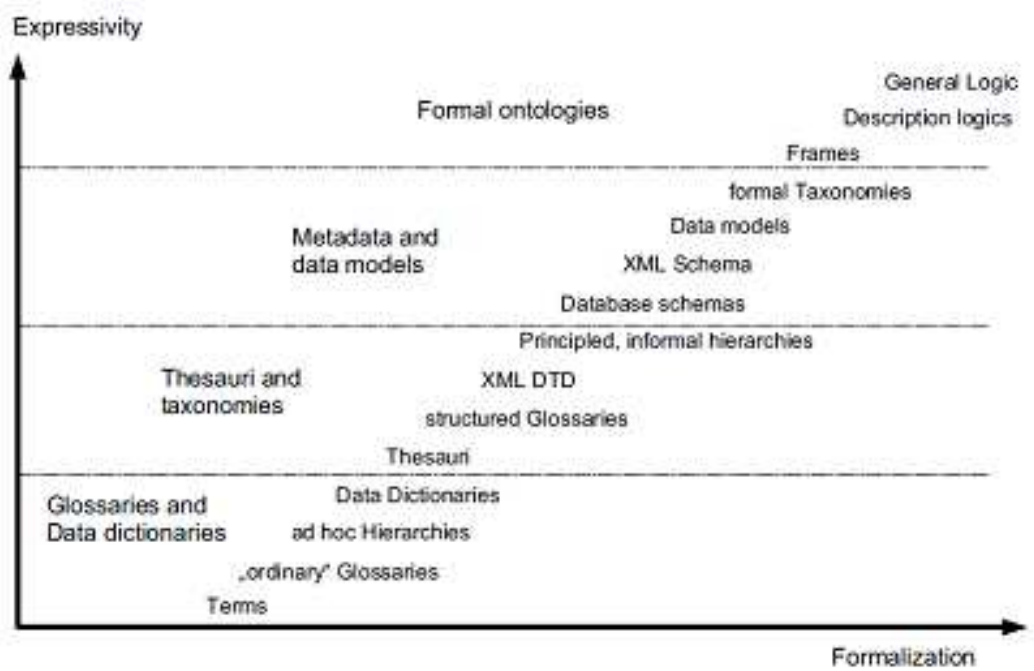

Figure 4 - Expressivity and formalization on ontologies - (Gasevic et al., 2006)

There are many potential applications of ontologies like collaboration, interoperation, education and modeling. Many researchers found that ontologies can help organizations in reducing complexity by modeling strategies and other organizational objects [33], like information systems and technology components [46]. 


\section{M\&S and Enterprise Maturity}

To implement M\&S and the related strategies like BPM and EA we have to consider many enterprise issues. The initiative is a challenge with technical and behavioral aspects. Thus we are talking about enterprise agility and maturity.

Enterprise maturity is a subject largely discussed in literature with well established standards like CMMI [10] and ISO [30]. Maturity is related with the capacity of coordinating Continuously Improving results [10]. Maturity is provided by repeatable, well-defined and managed programs.

The more a mature enterprise uses models the more mature it becomes. M\&S, BPM and EA are likely to succeed when IT is mature and there is enterprise-IT alignment.

IT maturity is also a large studied area and comprises well established standards, like COBIT [11] and ITIL [31].

Chen [7] proposes a framework for undestanding Business-IT Alignment. He identifies the alignment approaches: via architecture, via governance, and via communications. These three approaches are integrated in the BITAM-SOA Framework depicted in Figure 5.

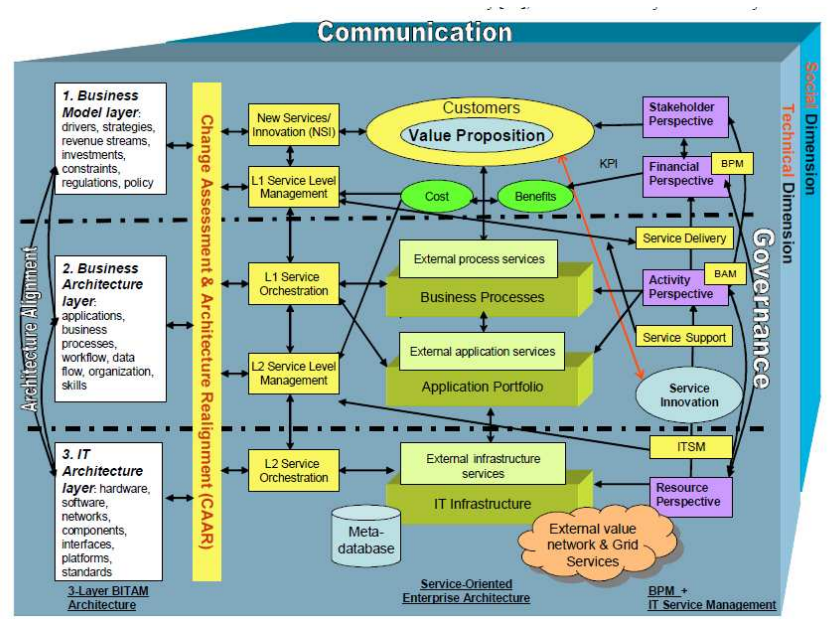

Figure 5 - BITAM-SOA Service Engineering Schematic (Chen, 2008)

Cumps, Viaene and Dedene [13] have identified the following approaches IT must have in order to contribute to Business-IT Alignment: Change management, Strategic IT planning, Risk management, Enterprise architecture management, Performance management, Program/portfolio management, Service-level management, Project management.

Enterprise Modeling is a collaborative process [55]. Business process (BP) change projects often involve the redesign of organizational information systems (IS). 
To successfully align the design of processes and IS, collaboration between BP and IS analysts is required [45]. To use models in structured way in the entire organizations cannot be reached without an organized effort [40].

Competence Centers are new forms of installing new cultures without centralized structures that inhibited creativity and collaboration. Competence centers can assign the right people, to determine processes and select the best technology [51]. Competence centers include many roles, persons and specialists without formal structure. Specialists meet in accordance with the demand. Benefits of competence centers, among others, are [27]:

- A team environment that fostered an increase in skills and competencies, along with employee retention.

- Standardized tools and approaches.

- Creation of metrics to measure integration, re-use, cost effectiveness and timeliness of deliverables.

- Relationships with key vendors and standards bodies to influence product direction.

- Business and marketing plans.

- Better managed resource allocation.

\section{Maturity in M\&S Strategies}

In previous sections we presented the integration of M\&S strategies with other approaches like BPM, EA and knowledge modeling. Concerning all the topics discussed, we can summarize the following:

- Enterprises are complex environments.

- M\&S, BPM, EA, and ontologies have much in common and must collaborate in an enterprise wide modeling approach.

- Each initiative has its complexity.

- Enterprise wide modeling approach is a complex effort.

- Each one of these approaches is still a promise for most organizations.

- Enterprise wide modeling efforts have a strong dependence on organizational collaboration.

- The enterprise integration issue of M\&S has had little attention in literature.

- The factors that help organizations succeed in M\&S strategies have also had little attention of researchers.

Business and system analysts may become confuse with the proliferation of techniques, languages and tools inside the organization. So, organization must have:

- A clear vision of the different technologies, their purposes and their integration.

- A well-defined program of implementation. 
- Best practices encouragement.

- Experiences consolidation.

- Continuous programs of research and improvement.

For succeeding in enterprise wide M\&S efforts, organization must have a framework for understanding the technology. There are many types of models and they relate one another to provide different visions and solutions. In figure 6, we present a framework that consolidates the concepts discussed.

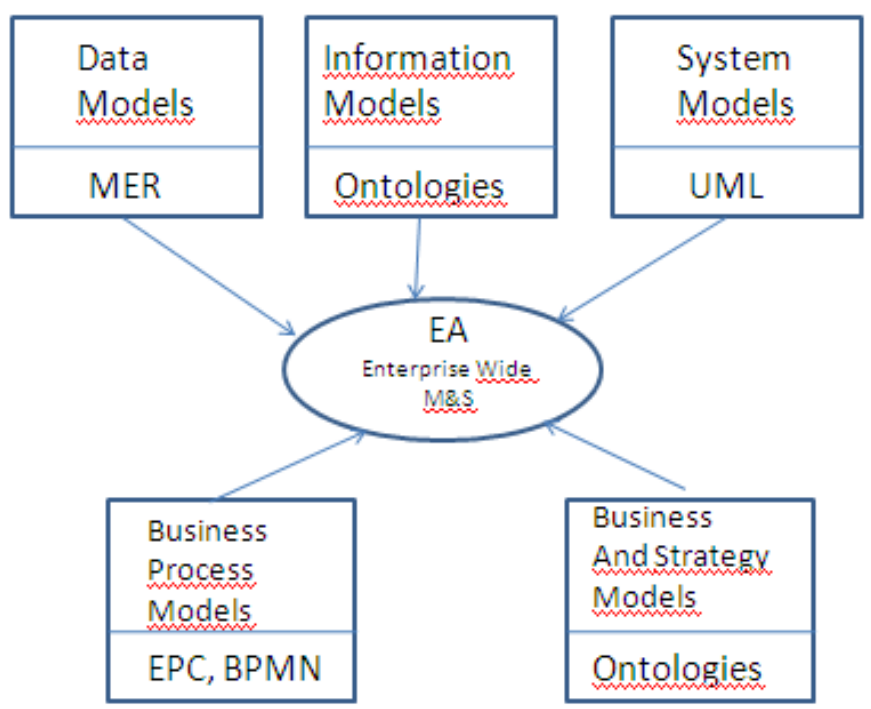

Figure 6 - Framework of Enterprise Models

In this framework, the traditional data, systems and process models are combined with information and knowledge models to help understanding all the complexity of the enterprise.

Besides understanding the technical relations of $M \& S$, enterprises need a mature strategy. M\&S programs need to be well defined, managed and repeatable. These programs need collaboration all over the enterprise. Thus, we propose a competence center approach as discussed in section 5 .

The Competency Center can be situated in business or IT. It must be a unity with few specialists at each time, allocated by necessity. Business analysts, business specialists, data administrators, designers, systems analyst are all candidates to participate.

The Competency Center will provide the unification of concepts, dissemination of culture, integration of initiatives, collection of experiences and reuse of knowledge. With the right vision of the technology and the vigilance of the competency center enterprise will be mature in $M \& S$ initiatives. They will be agile to change. 


\section{Conclusion and future works}

Enterprise environments are complex. Enterprise Modeling and related strategies can take control of this complexity. To succeed in $M \& S$, organizations must have an integrated vision and mature approaches.

This paper presented an integrated view of $M \& S$ and related technologies. It discussed the maturity aspects of enterprise and recommended a competency center approach in order to succeed in M\&S programs.

Enterprise wide $M \& S$ needs more research and practice. We are currently applying the concepts described in a case study. The experience gained in this work is providing us with a better idea of the requirements for succeed in M\&S wide initiatives. We hope to continue work on describing the applicability of the framework and on proposing new resources for tools integration and better strategies to enterprises.

Enterprises need maturity to control complexity and succeed. IT must be also mature and aligned with business. $M \& S$ initiatives need this alignment. Mature $M \& S$ initiatives can carry agility and better results to enterprises.

This is a fertile field of research. The complexity of enterprise wide M\&S efforts is a challenge. Few organizations succeed. We gave some insights to researchers and practitioners. Technology is evolving and we will continue searching new resources, methodologies and approaches. We encourage more researchers to do the same. We also encourage enterprises to embrace enterprise wide $M \& S$ initiatives. We are sure they will be more agile and mature and will succeed on competition.

\section{References}

1. Aguilar-Savén, R.S. Business process modelling: Review and framework. International Journal of Production Economics. 90, 129--149 (2004)

2. April, Jay and Better, Marco and Glover, Fred and Kelly, James and Laguna, Manuel. Enhancing business process management with simulation optimization. Proceedings of the 38th conference on Winter simulation. pp 642--649 (2006)

3. Booch G, Rumbaugh J, Jacobson I The Unified Modeling Language User Guide. Addison-Wesley, Reading, Massachusetts (1999)

4. Bosilj-Vuksic, Vesna; Ceric Vlatko. Criteria for the Evaluation of Business Process Simulation Tools Interdisciplinary Journal of Information, Knowledge, and Management . 2, 195-205 ( 2007)

5. Castle, J.A. An integrated model in quality management, positioning TQM, BPR and ISO 9000. The TQM Magazine. 8, 7--13 (1996)

6. Cao, Longbing; Luo, Chao,;Luo, Dan, Liu. Ontology Services-Based Information Integration in Mining Telecom Business Intelligence. Lecture Notes in Artificial Intelligence (Subseries of Lecture Notes in Computer Science). vol 3157, pp 8594, (2004)

7. Chen, Hong-Mei .Towards service engineering: Service orientation and businessIT alignment Proceedings of the Annual Hawaii International Conference on 
System Sciences, Proceedings of the 41st Annual Hawaii International Conference on System Sciences 2008, HICSS, (2008).

8. Chen, Peter Pin-shan. The Entity-Relationship Model - Toward a Unified View of Data. ACM Transactions on Database Systems. 1, 1--36 (1976)

9. Choo, Chun W. Information management for the intelligent organization: the art of scanning the environment. ASIS monograph series (1998)

10. CMMI Product Team (2002), Capability Maturity Model Integration (CMMI), Version 1.1, Staged Representation, CMU/SEI-2002-TR-029, ESC-TR-2002029, Software Engineering Institute, Carnegie Mellon University, Pittsburgh,Pennsylvania.

11. COBIT (2000), Control Objectives for Information and related Technology (COBIT), 3rd Edition. IT Governance Institute, Rolling Meadows, Illinois. http://www.isaca.org/cobit.htm.

12. Crosby, P. Quality is free. McGraw-Hill (1979)

13. Cumps, B.; Viaene, S.; Dedene, G.; Managing for Better Business-IT Alignment IT Professional . 8, 17-24 (2006)

14. Davenport H., Ecologia da Informação. São Paulo: Editora Futura (1998)

15. Delen, Dursun and Benjamin, Perakath C. Towards a truly integrated enterprise modeling and analysis environment. Computers in Industry.. 51, 257-268 (2003)

16. Deming, E. Out of crisis. MIT Press (1986)

17. Dietz, J. L. G. DEMO: Towards a discipline of organisation engineering. European Journal Of Operational Research. 128, 351--363 (2001)

18. Dragan Gasevic, Dragan Djuric,Vladan Devedzic. Model Driven Architecture and Ontology Development. Springer (2006).

19. Ecreus, K. ; Poels, G. Putting Business into Business Process Models. Computer Software and Applications, 2008. COMPSAC '08. 32nd Annual IEEE International . pp 1005--1010 (2008)

20. Elzinga, D.J. et al. Business process management - survey and methodology. Transactions On Engineering Management. Ieee-Inst Electrical Electronics Engineers Inc. .42, 119-128 (1995)

21. Evernden, R.The Information FrameWork. IBM System Journal. 35, 37--68 (1996)

22. Evernden, Roger; Evernden, Elaine. Information First: Integrating Knowledge and Information Architecture for Business Advantage. Butterworth-Heinemann, London (2003)

23. FEAPMO (2004), Federal Enterprise Architecture, http://www.feapmo.gov.

24. Giaglis, G. M. A Taxonomy of Business Process Modeling and Information Systems Modeling Techniques. International Journal of Flexible Manufacturing Systems. 13, 209--228 (2001)

25. Gruber, T.R. A translation approach to portable ontology specifications, Knowledge Acquisition. 5, 199-220 (1993)

26. Hammer, Michael \& Champy, James. Reengineering the Corporation: A Manifesto for Business Revolution. HarperBusiness, New York (1994)

27. HP. HP Integration Competency Center ftp://ftp.hp.com/pub/services/integration/info/integration_competency.pdf 
28. IDEF Integration Definition for Function Modeling (IDEF0) Draft, Federal Information Processing Standards Publication FIPSPUB 183. U.S. Department of Commerce, Springfield, Virginia. (1993)

29. Indihar-Stemberger, Mojca, Pppovic, Ales. Simulation and Information Systems modeling; Framework for business process change. http://scseurope.net/services/ess2003/PDF/BUS06.pdf.

30. ISO. Quality Management Systems - Requirements, ISO 9000:2000, International Organization for Standardization, Geneva (2000)

31. ITIL. "ITIL® Service Management Practices: V3 Qualifications Scheme" http://www.itil-officialsite.com/nmsruntime/saveasdialog.asp?IID=572\&sID=86. Retrieved on 2009-02-24.

32. Jussupova-Mariethoz, Helena; Probst, Andre-Rene .Business concepts ontology for an enterprise performance and competences monitoring. Computers in Industry $58,118--129$ (2007)

33. Lankhorst, Marc et al. Enterprise architecture at work - Modelling, communication and analysis. Springer, Heilderberg (2005)

34. Lindsay, A.; Downs, D.; Lunn, K. Business processes-attempts to find a definition. Information and Software Technology, 45, 1015-1019 ( 2003)

35. List, Beate and Korherr, Birgit. An evaluation of conceptual business process modelling languages. Proceedings of the 2006 ACM symposium on Applied computing. pp 1532-1539 (2006)

36. Melão, N.; Pidd, M. A conceptual framework for understanding business processes and business process modelling. Information Systems Journal. 10, 105-129 ( 2000)

37. McGaughey, Ronald E.; Gunasekaran, Angappa. Enterprise Resource Planning (ERP): Past, present and future.International Journal of Enterprise Information Systems. 3, 23--35 (2007)

38. McGovern, James ; Ambler, Scott W.; Stevens, Michael E. ; Linn James; Sharan, Vikas; Elias K. Jo. A Practical Guide to Enterprise Architecture Prentice Hall (2003)

39. Miers, Derek. The Keys to BPM Project Success. BPTrends January 2006. http://www.bptrends.com/publicationfiles/01-06-ART-KeysToBPMProjSuccessMiers.pdf. (2006)

40. Miers. Derek, An Introduction to BPM Suites. http://www.bptrends.com/reports_landing.cfm ( 2006).

41. Mylopoulos ,J.; Chung, L.; Yu, E. From object oriented to goal-oriented requirements analysis. Communications of the ACM. 42, 31--37 (1999)

42. OMG. Unified Modeling Language (UML), Version http://www.omg.org/docs/formal/07-11-04.pdf. last access 02-03-2009. (2003)

43. OMG. Business Process Definition MetaModel http://www.omg.org/docs/dtc/0707-01.pdf (2007)

44. Ould, M.: Business Process Management: A Rigorous Approach. British Computer Society , London (2005)

45. Paul, R.J. Serrano, A. . Collaborative information systems and business process design using simulation, 2004. Proceedings of the 37th Annual Hawaii International Conference on System Sciences. pp 10--15 (2004) 
46. Rebstock, Michael; Fengel, Janina; Paulheim Heiko. Ontologies-Based Business Integration. Springer (2008)

47. Ross, Jeanne W.;Weill, Peter; Robertson David. Enterprise Architecture As Strategy: Creating a Foundation for Business. Harvard Business School Press, New York (2006)

48. Sarasevic, Tefko. Information Science. Journal of the American Society for Information Science. 50, 1051--1063 (1999).

49. Scheer, A.W.; Nuttgens, M. Aris architecture and reference models for business process management. Business Process Management, Springer-Verlag Berlin, vol. 1806, pp. 376-389 (2001)

50. Scheer, A-W Business Process Engineering: Reference Models for Industrial Enterprises, 2nd Edition. Springer, Berlin. (1994)

51. Schmidt, John; Lyle, David. Integration Competency Center: An Implementation Methodology. Informatica (2005)

52. Silver, Bruce. http://www.brsilver.com/wordpress/category/bpms/

53. Smith Howard, Fingar Peter. Busines Process Management - The Third Wave. Meghan-Kiffer Press (2003)

54. Stephen,A. White. Introduction to BPMN. http://www.bpmn.org/Documents/Introduction\%20to\%20BPMN.pdf

55. Taylor, James C. Participative design: linking BPR and SAP with an STS approach. Journal of Organizational Change Management, 11 (3), 233--245 (1998)

56. The Open Group (2002), The Open Group Architectural Framework (TOGAF) Version 8 'Enterprise Edition'. The Open Group, Reading, UK.http://www.opengroup.org/togaf/.

57. van der Aalst, W. M. P. ; van Hee K. M. Business process redesign: A Petri-netbased approach. Computers in Industry. 29, 15--26 (1996)

58. van der Aalst, W. M. P. ; ter Hofstede, A. H. M., YAWL: Yet another workflow language . Queensland Univ. Technol.,Brisbane, Australia, QUT Tech. Rep., FIT-TR-2003-04 (2003)

59. Vergidis, K. Tiwari, A. Majeed, B. Business Process Analysis and Optimization: Beyond Reengineering. Transactions on Systems, Man, and Cybernetics. IEEE Publication, Vol: 38, Issue: 1, pp 69-82 (2008)

60. Weske, Mathias. Business Process Management: Concepts, Languages, Architectures. Springer (2007)

61. Zachman JA. A Framework for Information Systems Architecture.IBM Systems Journal. 26(3), 276--292 (1987). 